\title{
O DUALISMO MENTE-CORPO COMPATÍVEL COM A CONCEPÇÃO CIENTÍFICA DO MUNDO NO PENSAMENTO DE CHALMERS
}

\author{
RAFAEL SILVA SOUSA ${ }^{1}$
}

RESUMO: Através do pensamento de um dos mais influentes pensadores da filosofia da mente de nosso tempo, o filósofo australiano David John Chalmers, esse trabalho apresentará uma visão dualista da consciência que possibilita o desenvolvimento de teorias não reducionistas da consciência. Para esse propósito, faremos inicialmente uma distinção entre os problemas pertencentes ao desempenho de funções cognitivas com aqueles que envolvem os estados qualitativos da experiência, qualias. Segundo Chalmers, esses problemas estão inseridos, respectivamente, no chamado problema fácil e problema difícil da consciência. Por fim, após contrastar os problemas apresentados e com objetivo de demonstrar que a ciência empírica ainda não deu conta dos mistérios que envolvem o aspecto fenomênico da consciência, três princípios de Chalmers serão apontados como aspirantes a uma teoria da consciência que engloba tanto os processos físicos do cérebro como também os aspectos fenomênicos da consciência.

PALAVRAS-CHAVE: Consciência. Experiência. Problema.

\begin{abstract}
Through the thinking of one of the most influential thinkers of the philosophy of mind of our time, the Australian philosopher David John Chalmers, this work will present a dualistic view of consciousness that enables the development of non-reductionist theories of consciousness. For this purpose, we will initially make a distinction between the problems pertaining to the performance of cognitive functions with those involving the qualitative states of experience, qualias. According to Chalmers, these problems are inserted, respectively, into the so-called easy problem and difficult problem of consciousness. Finally, after contrasting the problems presented and with the aim of demonstrating that empirical science has not yet dealt with the mysteries surrounding the phenomenal aspect of consciousness, Chalmers's three principles will be pointed out as aspiring to a theory of consciousness that encompasses both physical processes of the brain as well as the phenomenal aspects of consciousness.
\end{abstract}

KEYWORDS: Consciousness. Experience. Problem.

\section{1 - Introdução}

O campo dos estudos da consciência vem se tornando desde a segunda metade do século XX uma área bastante apreciada, talvez porque muitos cientistas consideram os mistérios da consciência como um dos poucos ou últimos vestígios remanescentes sem uma resposta clara e simples tão exigida pela ciência. E como nada no universo parece ser tão misterioso quanto o funcionamento interno da mente humana, a filosofia não poderia ficar distante dessa causa. Lembremos o aforismo "'conhece-te a ti mesmo", uma simples 
declaração, porém com vastas ramificações que mostram que a tentativa de compreender a consciência sempre foi um imperativo no pensamento filosófico.

Por conta disso, irei apresentar teses de um dos pioneiros e um dos mais importantes pensadores de nosso tempo, o filósofo australiano David John Chalmers (1966 - ). Com ele, veremos, por meio de uma diferenciação de problemas da consciência, os chamados 'easy problem" e "hard problem"' (problema fácil e problema difícil), que ainda existem mistérios não solucionados quando se trata de nossa consciência.

O fácil problema da consciência será visto aqui como um problema pertencente à entrada, saída de dados e demais funções de nosso cérebro que, segundo Chalmers, são respondidos usando os métodos usuais da ciência. Já no caso do chamado difícil problema da consciência, veremos que esse problema faz justiça ao nome, uma vez que ainda nos falta uma explicação clara de como nossa experiência subjetiva pode surgir ou ser explicada a partir de processo físicos. Por meio disso, opondo-se às abordagens excessivamente redutoras da consciência, apresentarei os argumentos e teses de Chalmers que fundamentam a ideia de que para termos uma resposta satisfatória ao enigma da consciência, devemos não apenas levar em consideração o aspecto físico (material), mas também o aspecto fenomênico da consciência.

As objeções ao ponto de vista dualista de Chalmers serão tratadas em outra oportunidade, uma vez que o objetivo maior do presente trabalho será o de apresentar os argumentos de Chalmers contra as abordagens totalmente reducionistas da consciência e provocar o seguinte questionamento sobre a natureza da mesma: nossa consciência é um fenômeno natural que depende inteiramente de processos cerebrais ou nela existem propriedades psicofísicas que não são reduzidas a propriedades físicas do cérebro?

\section{2 - Os dois problemas associados à consciência}

Chalmers vê a necessidade de esclarecer questões importantes no debate mentecérebro; em seu artigo intitulado Facing Up the Problem of Consciousness (Enfrentando o Problema da Consciência) publicado em 1995, ele nos diz:

Não existe nada que conhecemos tão intimamente quanto a experiência consciente, mas não existe nada tão difícil de explicar. Todos os tipos de fenômenos mentais têm se entregado à investigação científica nos últimos anos, mas a consciência tem teimosamente resistido. Muitos tentaram explicá-la, mas as explicações parecem sempre ficar aquém do alvo. Alguns foram levados a supor que o problema é intratável e que nenhuma boa explicação pode ser dada. (CHALMERS, 1995, s.p) 
A partir disso, David Chalmers vai adotar o problema e introduzir um elemento novo no debate sobre a consciência, ele acredita que há dois problemas de consciência que se dividem em problemas fáceis e problemas difíceis. O primeiro refere-se às funções de entradas e saídas no cérebro, o trabalho de linguagem e como nosso cérebro processa a integração e organização de nossas experiências, em outras palavras, como conseguimos discriminar estímulos sensoriais reagindo de forma apropriada e como conseguimos verbalizar os nossos estados internos. O segundo questiona o aspecto causal de nossa consciência, ou seja, como um processo físico pode causar experiências subjetivas e se há possibilidade de um inconsciente autônomo executar processos cerebrais.

As características dos problemas fáceis da consciência podem ser explicadas usando os métodos usuais da ciência, pois são eles diretamente suscetíveis aos métodos padrão da ciência cognitiva. Porém, a consciência parece marcar os limites do que a ciência pode explicar ao nos oferecer problemas que parecem resistir aos métodos científicos. Para Chalmers, esses estão inseridos no problema difícil da consciência, que é um problema de experiência e refere-se ao caráter fenomênico da mente, ou seja, aos processos físicos no cérebro que dão origem às experiências subjetivas da mente e do mundo:

O problema verdadeiramente difícil da consciência é o problema da experiência. Quando pensamos e percebemos, há uma grande quantidade de processamento de informação, mas também há um aspecto subjetivo. Tal como Nagel (1974) colocou a questão, há algo como é ser um organismo consciente. Este aspecto subjetivo é a experiência. Quando vemos, por exemplo, experimentamos sensações visuais: a qualidade sentida do vermelho, a experiência do escuro e da luz, a qualidade da profundidade num campo visual. [...] O que une todos estes estados é que há algo que é estar nesses estados. Todos eles são aspectos de experiência. (CHALMERS, 1998, p. 10)

Podemos ver que o problema difícil da consciência envolve o porquê de nossas experiências neurológicas virem acompanhadas por uma vivência interna. Trata-se aqui da dificuldade de explicar as sensações qualitativas, comumente designadas por qualias (qualidades fenomênicas). É nesse problema que Chalmers vai dar mais ênfase e, por conta disso, veremos com mais profundamente adiante.

Chalmers considera que os fáceis problemas consciência são respondidos pela psicologia, neurociência e que as diversas pesquisas atuais sobre a consciência estão todas voltadas para os problemas fáceis. Esses problemas envolvem a capacidade de explicar como discriminamos, categorizamos e reagimos a estímulos ambientais, como ocorre a reportabilidade dos estados mentais, a capacidade de um sistema de acessar seus próprios 
estados internos, a distinção entre sono e vigília etc. Para Chalmers há uma multiplicidade de abordagens e experimentos empíricos que oferecem explicações apropriadas para uma grande demanda de questionamentos, mas todos eles envolvendo apenas problemas que estão inseridos no problema fácil da consciência. Por conta disso, foi o problema difícil da consciência que causou um alvoroço entre neurocientistas, psicólogos e filósofos, propiciando o surgimento de diversas teorias emaranhadas que deram um papel fundamental para o raciocínio filosófico. E corolário do posicionamento de Chalmers vai desde a negação total de sua teoria à redução naturalista, pampsiquismo ${ }^{2}$ e dualismo mente - corpo.

Assim, para progredir no problema da consciência, o autor se preocupa em demonstrar que os mais recentes trabalhos que tentam abordar questões acerca da consciência não conseguem dar conta da parte mais difícil do problema por meio de métodos reducionistas. Conforme Chalmers:

O que torna difícil o problema difícil é que ele vai muito além dos problemas sobre o desempenho de funções. Para ver isso, note que mesmo quando explicamos o desempenho de todas as funções cognitivas e comportamentais que estão na confinidade da experiência - discriminação perceptual, categorização, acesso interno, relato verbal - ainda pode haver uma pergunta que não foi respondida: por que o desempenho dessas funções é acompanhado pela experiência? (CHALMERS, 1995, s.p)

Algumas experiências são apontadas para reforçar a sua tese de que a neurociência e diversos outros trabalhos relacionados às ciências cognitivas só podem dar conta daquilo que é considerado como problema fácil. Ou seja, Chalmers diz que podemos explicar muito bem o acesso e a reportabilidade (ou comunicabilidade) dos estados mentais por meio de mecanismos computacionais ou neurais, destacando a estrutura de onde a informação sobre esses estados internos é recuperada e concedida a relato verbal. Da mesma forma, é completamente possível explicar uma integração de informação pelo sistema cognitivo, para isso basta expor os mecanismos pelos quais é reunida a informação e utilizada por processos posteriores. Até mesmo se tratando do sono e vigília, sabemos que hoje diversos laboratórios de neurofisiologia se utilizam de equipamentos como o eletroencefalograma para registro de variáveis eletrofisiológicas da atividade elétrica cerebral onde é possível analisar objetivamente toda a estrutura material do indivíduo enquanto dorme. Portanto, o que Chalmers parece querer dizer levando em consideração as pesquisas atuais é que não há muitos mistérios naquilo em que a ciência já tem uma boa explicação.

Como apontado por Chalmers, o difícil problema da consciência se torna difícil porque não se trata de desempenho de funções cognitivas. Ele é diferente do problema fácil, pois esse pode ser solucionado através de uma explicação materialista reducionista pelo qual a 
ciência se apossa e manifesta-se eficientemente. Por exemplo, um gene pode ser explicado especificando o mecanismo que armazena e passa nossas informações hereditárias para diversas gerações. Função essa que é desempenhada pelo ácido desoxirribonucleico (DNA); portanto, ao explicarmos como a função do DNA é processada, explicamos o gene. Podemos explicar um organismo vivo através de relatórios sobre sua reprodução, adaptação ao ambiente, desenvolvimento etc. Todos esses problemas de desempenho de funções, segundo Chalmers, podem ser resolvidos através de uma abordagem reducionista, porém, o problema difícil da consciência permanece intocável mesmo quando todas as funções e habilidades cognitivas são explicadas.

Quando se trata de explicar o problema difícil da consciência estaremos lidando com estados qualitativos da experiência, os qualias. Chalmers acredita que a ciência e a filosofia ainda não foram capazes de nos dar uma explicação satisfatória para a noção de qualia. Isso quer dizer que a dificuldade está em explicar como e porque os processos físicos do cérebro dão origem às experiências subjetivas; em outras palavras, se trata como pensamos e percebemos as coisas. Por exemplo, porque a dor que uma pessoa sente quando está fazendo uma tatuagem é diferente da dor de outras pessoas se teoricamente todos passam pelo mesmo processo físico cerebral? Como explicar o fato do cheiro da gasolina ser agradável para mim e para outras pessoas ser enjoativa? Porque temos emoções tão diferenciadas nas mesmas condições causais? Ao que parece, e por mais absurdo e irracional que pareça, nossos processos físicos originam um tipo de vida interior. Então, em vista disso, Chalmers nos diz que se existe um problema verdadeiramente desafiador que se caracteriza como problema da consciência, esse é o problema.

O problema difícil da consciência que Chalmers nos apresenta parece nos deixar um vazio explicativo entre o mundo físico e a consciência. Em função disso, esse problema está sendo um eixo de bastantes discussões na filosofia da mente. Para Chalmers, o que há de comum em todos os estados qualitativos da consciência é o que os une, todos eles são estados de experiência. E a abordagem reducionista pelo qual a ciência se apropria mostrou não ser suficiente para fornecer uma explicação satisfatória ao aspecto fenomênico da consciência, talvez porque a consciência não possa ser funcionalmente explicada. Por conta disso, Chalmers percebeu a necessidade de uma nova abordagem que seja capaz de atingir a esfinge do problema difícil da consciência, isto é, uma nova receita para nos dar uma explicação suficientemente clara de como se dá a ligação de nossos processos cerebrais com as experiências subjetivas em uma única entidade. Em outras palavras, como explicar a interação 
dualista entre estados mentais (consciência) e processos cerebrais? Chalmers batizou esse enigma como o problema da experiência consciente.

\section{3 - As teses de Chalmers: uma busca por respostas}

Em seu artigo 'The puzzle of conscious experience"' (O enigma da experiência consciente) publicado originalmente em 1995, Chalmers argumenta que as posições reducionistas da consciência e as posições céticas de impossibilidade de sua compreensão estão erradas e, dessa forma, a solução para o enigma da consciência encontra-se em algum lugar no meio dessas posturas. No entanto, levando em conta nossa leitura das páginas anteriores desse artigo, esse posicionamento já era esperado, não é mesmo?

O desafio aqui é fornecer uma descrição da experiência consciente, ou seja, a descrição de uma vida mental privada e subjetiva oriunda da experiência. Mas como isso é possível? Chalmers é bastante franco quanto a isso; segundo ele, os detalhes minuciosos para tal descrição sobre o aspecto subjetivo do mental ainda se encontram imersos em nossa realidade. Porém, podemos inferir um posicionamento bem fundamentado sobre a questão, uma vez que, possivelmente, uma luz no fim do túnel para essa questão dependa de novos instrumentos de explicação que vá além das teorias físicas. Por conta disso, uma solução para esse problema pode trazer à teoria da consciência "'consequências espantosas no que diz respeito à nossa visão do universo e de nós próprios" (CHALMERS, 2002, p. 92).

Um dos maiores obstáculos para o surgimento de uma nova teoria da consciência é, sobretudo, a escassez de dados objetivo, ou seja, ainda não é possível observar a experiência consciente em um contexto experimental para gerar dados sobre a relação entre propriedades físicas e a experiência. No entanto, Chalmers nos diz:

Todos nós temos acesso a uma rica fonte de dados quando é esse nosso próprio caso. Muitas regularidades importantes entre experiência e processamento podem ser inferidas a partir de considerações sobre a própria experiência. Há também boas fontes indiretas de dados provenientes de casos observáveis, como quando se confia nas descrições que um sujeito faz de sua própria experiência. Esses métodos têm suas limitações, mas eles nos oferecem mais do que o suficiente para obtermos uma teoria bem fundamentada'”. (CHALMERS, 1995, s.p)

Em função dessa impossibilidade de testes experimentais intersubjetivos conclusivos, essas teorias manterão um "status" de especulação. Apesar disso, Chalmers diz que para a avaliação de tais teorias, podemos elaborar teorias compatíveis com os dados que temos e examiná-las comparando umas com outras. Em outras palavras, mesmo sem acesso a uma 
observação intersubjetiva, podemos avaliar uma teoria utilizando a simplicidade, coerência interna, coerência com outras teorias, capacidade de reproduzir atributos da experiência que nos são familiares etc. Com isso, diz Chalmers, podemos lançar teorias plausíveis e boas candidatas para dar uma explicação ao enigma da experiência consciente.

Dessa forma, Chalmers nos apresenta suas teses candidatas a uma teoria psicofísica da consciência, teoria que considera a experiência consciente como uma propriedade irredutível a algo mais simples; ou melhor, teoria que conjectura a existência de uma propriedade psicofísica que não se reduz à estruturas cerebrais. A primeira tese de Chalmers trata da coerência entre a estrutura da consciência e a estrutura do "estar-ciente",3 (awareness); isto é, para Chalmers, sempre que há estar-ciente (awareness), há consciência. Há uma correspondência mútua entre consciência e estar-ciente (awareness) onde a experiência de cada sujeito pode, pelo menos em parte, ser caracterizada e analisada por meio de relações de semelhança e diferença, localização, intensidade, estrutura geométrica etc. Por exemplo, o fato de podermos discriminar, nomear as cores e realizar diversas ações com os pigmentos referentes às cores de um mosaico nos sugere que as estruturas que podemos captar em uma experiência visual corresponde a uma estrutura de informação disponível no cérebro através dos processos neuronais do estar-ciente (awareness).

Chalmers também nos apresenta o chamado princípio da invariância organizacional. Esse princípio defende que sistemas com experiência consciente, mesma organização funcional, terão experiências qualitativas idênticas. 'Por exemplo, se as interações exatas entre nossos neurônios pudessem ser duplicadas através de chips de silício, a mesma experiência consciente surgiria' (CHALMERS, 2002, p.98). Essa posição funcionalista de Chalmers sustenta a tese de uma inteligência artificial por dar relevância a um padrão abstrato de interação causal em um sistema e não a uma composição física específica de um sistema.

Por exemplo, se eu construo um androide com um sistema sofisticado de chips de silício para realizar a função de meus neurônios e, de fato, os chips operam de forma semelhante a meus neurônios de meu cérebro, então, o comportamento de meu robô será semelhante ao meu. Mas, eis a questão, meu robô estaria consciente do mesmo modo que estou? Se meu robô reproduzisse uma experiência diferente da minha, apenas um de nós seria um organismo consciente ou seríamos ambos conscientes com experiências diferentes? Para Chalmers, se as mudanças de comportamento realmente corresponderem a mudanças de processamento, não há possibilidade de meu robô ter uma experiência consciente diferente da minha. Nesse caso, apesar do autor considerar a experiência consciente como um fenômeno 
natural que pode ir muito além dos fenômenos físicos, ele parece não discordar da ideia de que um tipo de consciência pode sobreviver em fenômenos físicos como em um robô.

Por último, Chalmers no apresenta a tese do princípio do duplo aspecto da informação que, segundo ele, possui um alto grau especulativo. Esse é o princípio que considera que a noção de informação é dividida em um duplo aspecto, um fenomênico e um físico. É evidente que almeja apontar uma correlação entre os fenômenos físicos que são observados, descritos e amparados pela ciência e as experiências subjetivas que são objetos internos.

Chalmers argumenta que a natureza intrínseca das entidades é ignorada pela física, e que alguns declaram que tais propriedades podem inexistir; porém, é completamente possível que a experiência consciente possa ter um elemento sutil de relevância causal se levarmos em consideração a hipótese que propriedades fenomênicas (ou experienciais) são o aspecto interno da informação. Com isso, "'podemos encontrar a mesma informação abstrata gravada no processamento físico e na experiência consciente"' (CHALMERS, 1995, s.p).

Essas conjecturas apresentadas por Chalmers são algumas ${ }^{4}$ candidatas para uma teoria da consciência que engloba tanto os processos físicos de nosso cérebro como também os aspectos fenomênicos da consciência, os estados mentais. Claro, Chalmers apenas nos oferece especulações para um problema difícil, podendo estar elas equivocadas ou em um bom caminho para se tornarem uma teoria consistente.

Vimos até aqui uma busca por respostas para aquilo que ainda permanece um mistério. Obviamente o raciocínio de Chalmers não esteve imune a críticas, críticas que abordarei em outra oportunidade. Mas, todavia, há de se considerar que David Chalmers introduziu novos e eficazes problemas que nos faz acreditar que o problema difícil da consciência pode ter uma resposta convincente em um futuro não muito distante.

\section{4 - Conclusão}

Com Chalmers, conseguimos apresentar uma pequena noção da complexidade do fenômeno da consciência do ponto de vista dualista. Ele realiza uma verdadeira expedição para saber qual a natureza e o lugar da consciência em nosso mundo físico através de uma proposta pluralista de que, para resolvermos questões difíceis sobre a consciência, devemos nos basear na ciência empírica, filosofia e na própria intuição.

Pudemos notar que o difícil problema da consciência, diferentemente do chamado fácil problema, é o problema mais importante na compreensão da mente, uma vez que até agora o materialismo não forneceu uma visão suficientemente clara para o problema da consciência. 
Portanto, por meio de suas teses, podemos concluir que Chalmers sugere que uma teoria não reducionista da consciência deve ser composta também por um conjunto de princípios psicofísicos, que são princípios que interligam as estruturas dos processos físicos de nosso cérebro com as nossas propriedades da experiência. Com isso, Chalmers se opõe a completa redução fisicalista, desafia a visão cientificista predominante no mundo e, principalmente, contribui para dar um novo ar aos debates clássicos sobre a mente.

\section{NOTAS}

1 Graduado em Filosofia pela Universidade Federal do Piauí (UFPI). Pós-graduando em Filosofia pela Universidade Federal do Piauí (UFPI). E-mail: rafaelmotorhead@gmail.com.

${ }^{2} \mathrm{O}$ Pampsiquismo defende que entidades físicas implicam ou podem implicar, em última análise, em elementos da consciência. Ou seja, o pampsiquismo afirma que tudo, todas as partes da matéria, pode ser reduzido ao mental.

${ }^{3}$ Chalmers utiliza o termo consciousness (consciência) para referir-se à experiência subjetiva, equivalente a "estar consciente de algo" e awareness como equivalente a "'estar ciente de" ou "ter ciência de". Awareness pode ser entendida como uma propriedade psicológica associada à experiência para referir-se a fenômenos que são facilmente acessíveis e relatados pela ciência, ou, sem grandes pormenores, como um estágio em que observamos um objeto, mas não temos uma consciência completa dele. Utilizarei o termo "estar-ciente" seguido do termo awareness em parênteses para fazer essa sutil distinção e evitar ambivalências.

${ }^{4}$ Chalmers acredita que o princípio de coerência estrutural e o princípio da invariância organizacional são fortíssimos candidatos para uma teoria satisfatória da consciência. Já no caso do aspecto duplo da informação, Chalmers argumenta que é ainda uma ideia distante, imatura.

\section{REFERÊNCIAS BIBLIOGRÁFICAS}

BONJOUR, L \& BAKER, A. Filosofia: Textos fundamentais comentados. Vários tradutores. $2^{a}$ Ed. Porto Alegre: Artmed, 2010.

CHALMERS, D.J. "Facing up to the Problem of Consciousness', In: Journal of Consciousness Studies, 1995. Disponível em: < http://consc.net/papers/facing.html > Acesso em: 20 de jan. 2017.

'Facing Up the Problem of Consciousness'. In: Explaining Consciousness

- The Hard Problem, The MIT Press, 1998, p.10.

'The puzzle of conscious experience'. In: Scientific American (The Hidden Mind), 2002, pp. 90-100.

KURZWEIL, Ray. Como criar uma mente: os segredos do pensamento humano. Tradução de Marcello Borges. São Paulo: Aleph, 2014.

LEÃO, Lúcia. Interlab : Labirintos do pensamento contemporâneo. São Paulo: Iluminuras, 2002.

MIGUENS, S. Compreender a mente e o conhecimento. Porto: U.Porto, 2009.

TEIXEIRA, J.F. Mente, cérebro e cognição. 3.ed. - Petrópolis, Rj: Vozes, 2008. 